BULLETIN Bulletin hispanique

HISPANIQUE Université Michel de Montaigne Bordeaux

$113-2$ | 2011

Varia

\title{
Begoña López Bueno (ed.), El Canon poético en el siglo
} XVII

Universidad, Secretariado de Publicaciones, Sevilla, 2010

\section{Nadine Ly}

\section{CpenEdition}

\section{Journals}

Edición electrónica

URL: http://journals.openedition.org/bulletinhispanique/1470

DOI: 10.4000/bulletinhispanique.1470

ISSN: 1775-3821

\section{Editor}

Presses universitaires de Bordeaux

\section{Edición impresa}

Fecha de publicación: 1 diciembre 2011

Paginación: 793-798

ISBN: 978-2-86781-793-9

ISSN: 0007-4640

\section{Referencia electrónica}

Nadine Ly, « Begoña López Bueno (ed.), El Canon poético en el siglo XVII », Bulletin hispanique [En línea], 113-2 | 2011, Publicado el 05 abril 2013, consultado el 22 septiembre 2020. URL : http://

journals.openedition.org/bulletinhispanique/1470 ; DOI : https://doi.org/10.4000/bulletinhispanique. 1470 
de J. M. Escudero (Kassel, Reichenberger, 2001). Una serie de erratas («Ignacio Feijoo», p. 63; "Covrarrubias», p. 146; "José Amescua», p. 211, n. 11, en vez de «Amezcua»; «quine», p. 211, etc.) podrían evitarse en posibles reediciones futuras. Se echa en falta una lista bibliográfica final que agrupe todos los estudios citados y que facilitaría la consulta del interesado. En general, la bibliografía es bastante completa y actualizada, aunque es notoria la falta de algunos trabajos de Enrique Rull sobre los estrechos vínculos entre algunos autos y comedias y su cronología, reunidos en Arte y sentido en el universo sacramental de Calderón (Pamplona / Kassel, Universidad de Navarra / Reichenberger, 2004), muy pertinentes para el séptimo capítulo. Entre otros, algunos estudios de interés no incluidos son: Suárez Miramón, A., «El sistema teológico-estético en Ficino y Calderón», en Edad de Oro Cantabrigense. Actas del VII Congreso de la Asociación Internacional del Siglo de Oro (Robinson College, Cambridge, julio 18-22, 2005), ed. A. Close, Madrid, AISO, 2006, pp. 579-584; B. Devos, «Calderón’s Ambiguity with respect to the Moriscos in El Tuzani de la Alpujarra», Anuario Calderoniano, 2, 2009, pp. 111-127; M. R. Greer, "Class and the Dirty Work of War in Calderón", Anuario Calderoniano, 2, 2009, pp. 207-218; J. Cruz Cruz, «La injuria al honor como motivación de la guerra según Vitoria, Molina y Suárez», Veritas, 54.3, 2009, pp. 13-33 (disponible en formato pdf. en: http:// revistaseletronicas.pucrs.br/ojs/index.php/veritas/article/view/6414/4680).

Obra de recopilación y creación, constituye, en suma, una buena despedida de su vida académica en activo y una aportación muy digna de tenerse en cuenta por la amplitud de temas abordados y el rigor analítico. Espero que, pese a los acordes de canto de cisne que suenan, el Dr. Güntert siga ofreciendo su saber por muchos años. So sei es denn.

Adrián J. SÁEZ

Begońa López Bueno (ed.), El Canon poético en el siglo XVII, Grupo PASO. - Sevilla, Universidad, Secretariado de Publicaciones, 2010, pp. 497.

Tercer volumen de una serie consagrada al «canon» por el grupo PASO (Poesía Andaluza del Siglo de Oro) es este un libro magistral por su extensión -le faltan dos páginas para llegar a las quinientas- y tanto por la pluralidad de aproximaciones (17 en total) como por la calidad y renombre internacional de los autores. Libro magistral, lo es también y, tal vez sobre todo, por su coherencia y carácter orgánico y por su dimensión exegética, erudita e histórico-crítica. Después de recordar que el proceso histórico de construcción del canon, para la poesía del Siglo de Oro, comienza, de manera 
sistemática, en el siglo XVIII, indicaba Begoña López Bueno, en el primer volumen de la serie (En torno al canon: aproximaciones y estrategias, 2005, 475 pp.): «[...] de eso se trata : de intentar comenzar delimitando el concepto poesía española del Siglo de Oro (e insisto en lo de concepto para resaltar que no se trata sólo de una realidad histórico-literaria, sino también de una construcción crítica), desde la propia época, desde las miradas contemporáneas que comenzaron ya a delimitar el corpus de las obras integrantes y tendieron a configurar el canon de ese corpus instituido» (p. 10). El proceso de construcción del canon en el siglo XVII se diferencia del anterior (El canon poético en el siglo XVI, 2008), cuyo norte estaba puesto en «los dechados grecolatinos con afán de recuperación», en que se efectúa "con el respaldo, ya español, de los autores anteriores renacentistas, ahora convertidos y sancionados como modelos». Como en el volumen anterior, junto a los trabajos de los miembros del grupo, se publican los de egregios especialistas invitados : Sagrario López Poza, Felipe Pedraza, Antonio Carreira, Rodrigo Cacho y Antonio Pérez Lasheras.

Esa imprescindible revisión de la historia del canon es cuestión que también empezó a debatirse en Burdeos, a iniciativa de François Lopez. En colaboración con Víctor Infantes y Pedro Ruiz, así como con colegas españoles, franceses, ingleses, italianos, portugueses, norteamericanos y con la Casa de Velázquez, se celebraron varios encuentros, cuyas actas se publicaron en la llamada serie "verde» del Bulletin Hispanique, uno de cuyos títulos es : La formation du Parnasse espagnol, XVE-XVIII siècle (2007), haciéndole eco el libro de Pedro Ruiz, de 2009 : El Parnaso versificado. La construcción de la república de los poetas en los Siglos de Oro.

El trazado del libro anterior (El Canon en el siglo XVI) contemplaba tres aspectos esenciales: «la relación con el canon estatuido previamente» a través de las traducciones, y los tratados de retórica y de poética; «los mecanismos contemporáneos puestos en juego para la constitución de un corpus poético ahormado en unas pautas canonizadoras» (impresos de autor, aprobaciones, defensas de la poesía lírica, «repertorios de ingenios» y justas poéticas); las fronteras, difíciles a veces de determinar, entre la poesía lírica y la poesía épica, satírica y burlesca. El trazado del libro actual presenta diferencias notables, como cabe en un todo orgánico cuyas partes reflejan realidades distintas y problemáticas nuevas.

Los testimonios del canon, aparecen ahora concretados en el consumo y la materialidad de los libros custodiados en las bibliotecas contemporáneas, como son las importantes bibliotecas, con número apreciable de libros de poesía, de Diego Sarmiento de Acuña, conde de Gondomar, Lorenzo Ramírez de Prado y Vincencio Juan de Lastanosa, analizadasas por Sagrario López 
Poza. Aparecen también transmitidos por los «profesionales» del territorio normativo de retóricas y poéticas, entre los que elige estudiar Begoña López Bueno a Bartolomé Jiménez Patón, Juan de Robles y Gonzalo Pérez de Ledesma, mientras que Jaime Galbarro García, dedicando a cada una de ellas una ficha descriptiva, ofrece una «catalogación de las retóricas españolas más importantes del siglo XVII», cuyo contenido evidencia la importancia de la oratoria sagrada, la hegemonía de la elocutio y la constitución de un canon contemporáneo. La contribución de José Manuel Rico García, «Sin poetas hay poéticas: los tratados de preceptiva literaria y el canon en el siglo XVII», a la vez que subraya el divorcio global entre práctica de la poesía y teoría poética le rinde homenaje a la rigurosa, moderna y documentada Ritmica de Caramuel (1665), "tratado de métrica de su tiempo», que convierte a los poetas excepcionales (Lope y Góngora) en canon de autores, ensalzados como «dos astros del Olimpo» y «una doble delicia del Parnaso». Evidencian el progreso poético y las resistencias a la innovación los textos críticos surgidos en torno a la polémica del Polifemo y las Soledades, cuyo «alcance doctrinal» analiza Juan Manuel Daza Somoano. La consolidación del canon, en cambio, se da en monumentos erudito-historiográficos como son los repertorios de libros y principalmente la República literaria de Saavedra Fajardo, la Junta de libros de Tamayo de Vargas y la Biblioteca Hispana Nova de Nicolás Antonio, que Francisco Javier Escobar inserta en el importante marco de la erudición en el siglo XVII..

La mayor fuerza canonizadora está vinculada a la difusión de los textos. El siglo XVII sanciona los dechados contemporáneos echando una mirada selectiva sobre la poesía del XVI, según demuestran las ediciones de poetas renacentistas entre 1600 y 1650, comentadas por Valentín Núñez Rivera con respecto a la polémica Garcilaso/Castillejo y a la gongorina, cuyos ecos siguen percibiéndose, a modo de "polémica encubierta» en las elecciones y omisiones de libros y poetas. También se publican numerosas antologías entre las que la Flor de diversa poesía de Madrigal, rescatada del olvido por Juan Montero, contrapesa las Flores de Espinosa otorgándole el primer rango de representación al sevillano Francisco de Medrano. Analizando las tipologías aprobatorias y la evolución del "censor burocrático» en "aprobador lírico», demuestra Ignacio García Aguilar («De Trento al Parnaso II: Aprobación textual y sanción poética en los poemarios impresos en el siglo XVII») que las aprobaciones dejan de ser meras censuras morales para convertirse en instrumento de "sanción poética». Volviendo al debate abierto acerca del modelo pragmático y estilístico de la poesía, cuestiona Pedro Ruiz Pérez, en "Género y autores : el giro en la cuestión de la poesía», la caracterización social del poeta y el lenguaje «destinado a dar cauce a la poesía de una manera 
canónica». Notables son la visión política desarrollada bajo el título «Del discurso nacional a la república de los poetas», con un texto significativo de Caramuel, y el repertorio de discursos en defensa de la poesía. A los «repertorios de ingenios» o listados de poetas dedica Francisco J. Álvarez Amo su estudio "Significado y función de los catálogos de poetas españoles del siglo XVII». Además de el Viaje del Parnaso (Cervantes), el Laurel de Apolo (Lope) y el Aganipe de los cisnes aragoneses (Ustarroz) se fija Álvarez Amo en los repertorios insertos en obras poético-narrativas y los catálogos en forma de epístola métrica. Recordando la conclusión de su anterior estudio relativo al siglo XVI, Inmaculada Osuna («Las justas poéticas en la primera mitad del siglo XVII») subraya la evolución de la "justa escolar, parroquial, gremial, cofrade, hasta la justa enmarcada en la fiesta ciudadana totalı. Un número mayor de justas públicas (presentadas en dos apéndices), geográfica y temáticamente diversificadas, y su papel determinante en la difusión de la poesía contribuyen a una mayor "visibilidad social» de la actividad poética, y confirman la valoración de poetas de primera fila.

La tercera y última parte del volumen, identificable aunque inserta, como las que preceden, en el fluido discurrir del libro, ofrece un espacio específico, individualizado, a los poetas más paradigmáticos, encabezados por la tríada Lope, Góngora, Quevedo y por Gracián. Felipe B. Pedraza Jiménez abre este espacio con «Lope de Vega y el canon poético». Después de presentar las definiciones de la palabra "canon», plantea la relación particular de Lope con el canon trazado para "transmitir a sus múltiples lectores una preceptiva poética» y "permitir al poeta que esboza esas reglas y perfila esos ideales incluirse a sí mismo dentro de la tabla de los auctores [...] como el primero de la lista» (p. 368). Proponiendo un catálogo de los escritos en que se abordan cuestiones de teoría literaria y poética (unos veinte títulos), concluye que esos escritos no son lo más importante de lo que trajo Lope, siendo su mayor aporte una "práctica revolucionaria", sin preceptos pero con posceptos (pp. 379-380), frutos del arte concebido como experiencia propia.

No sólo se publican y difunden apartir de 1627 las obras de Góngora, sino que se reimprimen varias veces en el siglo XVII, convirtiéndose su obra en canon por su permanente innovación y "excelsa calidad estética», como demuestra Antonio Carreira en «Góngora y el canon poético» (p. 396). En efecto, al primer gran canon poético del siglo de oro: «lo que venía de Italia» (p. 397), representado por Garcilaso que casi no encontró resistencia, «se superpone el segundo, más intenso y restringido: Góngora» (ibid.), que sí encontró resistencia, aunque decreciente. Pasando revista a todos los géneros cultivados por Góngora e indicando los modos de difusión y la singular influencia que ejercieron en la poesía lírica y dramática del XVII, nota 
Carreira que «los temas, el estilo y la calidad del poeta cordobés, en seguida fueron identificados como suyos, aun en textos inéditos y anónimos» (p. 399).

Rodrigo Cacho Casal («Quevedo y el canon poético español») recalca el carácter paradójico y la fragilidad del canon ilustrándolo por el caso de Quevedo «quien se ocupó de definir el canon poético español cuando lo vio amenazado por los ataques de algunos humanistas europeos o por las innovaciones del gongorismo, como se percibe en la España defendida y en los prólogos y dedicatorias a sus ediciones de 1631 de fray Luis de León y Francisco e la Torre» (pp. 421-422). Considerando la lírica como una modalidad sublime de la poesía, autodefiniéndose como «descompuesto componedor de coplas, señalado de la mano de Dios» (entre 1600 y 1605 , p. 422) e incluyéndose «en el gremio de los poetas a los que califica irónicamente de lunáticos y soñadores» (1635, pp. 422-423), Quevedo define unos presupuestos estéticos de los que se vale en las polémicas literarias en las que participó. El artículo muestra como los autores canónicos influyeron en la escritura de Quevedo y en las estrategias de autocanonización desplegadas por el poeta, consiguiendo así Quevedo -considerado en la Junta de libros de Tamayo como «escritor general»- la canonización en el mismo siglo XVII.

Apoyándose en un estudio publicado en La formation du Parnasse espagnol, Bulletin Hispanique (2007, T. 109-2), Antonio Pérez Lasheras cuestiona la visión que propone el tratado de Gracián, Agudeza y Arte de Ingenio, de lo que en su tiempo todavía no se llamaba «literatura espańola». Define las cinco líneas que vertebran esa visión y, en cuanto a la poesía, muestra que Gracián apuesta por la poesía basada en el ingenio, añadiendo también ejemplos no literarios de agudeza (anécdotas, actos y hechos agudos) que hacen de la obra teórica de Gracián un tratado total del ingenio.

Y ya para despedirnos del canon español y del libro, la apertura hacia América la lleva a cabo Ángel Estévez Molinero con el parnaso antártico ( $\mathrm{La}$ conformación del canon en la poesía hispanoamericana del siglo XVII»). Entre «la poesía manuscrita de Rosas de Oquendo (1598) y la impresión de la Fama, y obras póstumas de Sor Juana (1700), [...] son pocas las obras poéticas producidas en América que llegan a las prensas» (p. 476). Las condiciones no son favorables y la que canoniza es España. Por la colonia circulan sin embargo modelos cuya lectura tal vez permitió que se gestaran textos como, entre otros, la Miscelánea austral (1602) de Diego Dávalos, y el importante Apologético en favor de D. Luis de Góngora (1662) de Juan de Espinosa Medrano. Domina Góngora el canon español de los americanos, aunque se nombran también a muchos más, y los poetas americanos no vacilan en señalar a qué poeta están imitando. La única en escalar, en vida, 
a la cumbre del Parnaso, es Sor Juana, que frente a un Juan del Valle y Caviedes, que «se decanta por la agudeza de perspicacia ... a la manera de Quevedo [...], es un Lope conmovedor cuando poetiza, [...]; un Quevedo de hondura cuando tensiona el tiempo entre los versos; una ilustre gongorina cuando despliega [...] la agudeza de artificio en el Primero Sueño ...» (p. 495).

Están en preparación las actas del X encuentro internacional sobre poesía del Siglo de Oro : La «idea» de la poesía sevillana en el siglo de oro, en homenaje al Profesor López Estrada, organizado por el Grupo PASO y celebrado en Sevilla el pasado mes de noviembre.

Nadine LY

Juan Pablo Forner, Discurso sobre el modo de escribir y mejorar la historia de España. Prólogo de François Lopez. - Pamplona, Urgoiti, Editores, 2010.

Desde hace ya mucho tiempo, y de manera más concreta desde 1976, hablar de Juan Pablo Forner supone referirse a François Lopez, su redescubridor ${ }^{2}$. Y, también, al revés porque desde la publicación en Burdeos de su tesis de Doctorado, abordar cualquier aspecto sobre la vida y la obra de aquel erudito extremeńo ha supuesto y sigue suponiendo citar el mencionado estudio. Las razones por las cuales este hispanista francés con sangre espańola se apasionó con la trayectoria intelectual de un personaje oscuro que, según sus propias palabras, presentaba una violenta discordancia con los más reconocidos escritores que le eran contemporáneos, el mismo las esbozó en el prólogo de su obra, al señalar que si el encuentro fue fortuito, la decisión de adoptarlo fue fruto de la reflexión. Desde el primer momento su propósito fue ir más allá de una biografía convencional y trascender, como había hecho su admirado Lucien Febvre, del hombre al problema que, en este caso, no era otro que el peso de la tradición española en la Ilustración. En su búsqueda, se sumergió en el tiempo para leer sus escritos en los términos que le eran propios y, al hacerlo, quedó definitivamente prendido en las redes de su pasión polemista. No son estas, sin embargo, cuestiones en las que haya que extenderse a la hora de reseñar la reedición de uno de sus textos más significativos, pero resulta difícil abordarlo sin señalar antes que el Forner que hoy leemos es aquel que el profesor Lopez rescató de las muchas simplificaciones que lo oscurecían. Poco importa que estas

2. François Lopez, Juan Pablo Corner et la crise de la consciente espagnole au XVIII siècle, Burdeos, Université, 1976. Traducción española, Juan Pablo Corner (1756-1797) y la crisis de la conciencia española, Salamanca, Junta de Castilla y León, 1999. 